\title{
GOVERNING MAJOR EVENT LEGACY: CASE OF THE GLASGOW 2014 COMMONWEALTH GAMES
}

\author{
BRIONY SHARP* AND REBECCA FINKEL† \\ *Events Management, University of Huddersfield, Huddersfield, West Yorkshire, UK \\ †Events Management, Queen Margaret University, Edinburgh, UK
}

\begin{abstract}
This article explores the emerging importance of planning and governance surrounding the concept of event legacy by focusing on an in-depth case study of the Glasgow 2014 Commonwealth Games. Given the long-term nature of the concept of legacy, the need for planned and thorough pre-, during, and post-Games management is essential if legacy outcomes are to be monitored effectively. Research method employed for this study consist of in-depth interviews $(n=14)$ with policy makers, organizers, and local community associations who were involved with legacy planning and implementation for the Glasgow 2014 Commonwealth Games. The findings present Glasgow's legacy approach as an advancement in the understanding of legacy governance and planning in relation to critical event management. By designing and implementing legacy governance structures at an early stage, each stakeholder role is established and can be monitored while allowing for some flexibility within the legacy management partnerships. In addition, the notion of a partnership legacy can be seen to have grown from innovative legacy governance structures, such as collaborative working and network creation, put in place by Glasgow in the early stages of legacy planning, which can act as a model of best practice for other major event host destinations.
\end{abstract}

Key words: Major events; Legacy; Critical events; Planning; Governance

Introduction

In the context of major events, permanent or longterm impacts for a host city are often recognized as legacy (Thomson, Schlenker, \& Schulenkorf, 2013). The Scottish Government Games Legacy Team's (2009) publication suggested legacy is a relatively recent concept in the history of major sporting events, particularly legacy that is broader than economic impact. Areas often included within the legacy rhetoric are potential social, economic, physical, tourism, and/or environmental factors (Thomson et al., 2013). The importance of understanding legacy governance and planning is central to developing critical event legacy research by providing further investigation into how to successfully 
govern major events across multistakeholder partnerships and ensure thoughtful longitudinal legacy planning. The aim of this research is to critically evaluate the approaches taken surrounding legacy governance and planning among Glasgow 2014 Commonwealth Games (the Games) stakeholders. The stakeholders interviewed included individuals from the local authority, the Games Organizing Committee (OC), a social research organization, a national voluntary organization, and a local regeneration partnership. The findings from this research suggest the partnerships created for the Games have the potential to create a partnerships legacy that continues to be utilized post-Games. Furthermore, this research builds upon the work of a number of other scholars highlighting the importance of legacy planning from the bid state (Leopkey \& Parent, 2012) and establishing governance structures (Christie \& Gibb, 2015) to develop advancements in contemporary understanding of this emerging field.

In November 2007, Glasgow was announced as the city that would host the 2014 Commonwealth Games. From the bidding stage, a partnership between by Glasgow City Council and the Scottish Government made a concerted effort to demonstrate the potential benefits for the host community from hosting such an event (Christie \& Gibb, 2015). Therefore, a significant amount of Glasgow's winning bid to host the Games rested on their convincing argument to produce a successful event legacy for the city and people (McCartney, Hanlon, \& Bond, 2013). Developed by the Scottish Government and Glasgow City Council, the bid emphasized outcomes that would benefit the host population, collectively placed under the umbrella of legacy. There has been considerable interest recently in the notion of legacy and its relevance in contemporary major eventled governance (Christie \& Gibb, 2015; Clark \& Kearns, 2015; Smith, 2012). Aligned with this is the significant growth in the importance of governance and planning outcomes (Coaffee, 2013; McGillvray, MacPherson, \& Carnicelli, 2015); however, there is little evidence to support the concept of a lasting positive legacy from development associated with mega-events, and what evidence exists is fragmented and contested (Davies, 2012; Lenskyj, 2002). This research makes an original contribution to knowledge about event legacy by focusing on the planning and governance aspects, specifically regarding the Glasgow 2014 Commonwealth Games, which furthers understanding about the ways in which partnerships can create greater potential for impactful events legacy.

Emerging research from current major events, such as Glasgow's 2014 Commonwealth Games, suggests improvements in legacy areas including planning and governance (Christie \& Gibb, 2015), sustainability (Rogerson, 2016), planned legacy outcomes (McCartney et al., 2013), volunteering (Jones \& Yates, 2015), and community regeneration (Clark \& Kearns, 2015). From the time of announcement as the 2014 Commonwealth Games host, Glasgow made their legacy promise clear. Published in 2009, the Glasgow 2014 Legacy Framework (GLF) declared the Games would produce a sustainable legacy, and it would be a "People Legacy" (Glasgow City Council 2009, p. 3). Glasgow's concentrated effort to produce a legacy from the Games provides a timely example to explore the potential to secure such legacy benefits often heralded by host cities without much proof (McCartney et al., 2013). By collecting empirical data aligned with emerging critical event discourses, this study seeks to locate legacy governance as a crucial element of major event legacy planning.

For this research, importance is placed on the approach taken specifically in Glasgow by the City Council; however, this is not without regard to the governmental contribution. Specifically, it is worth noting the vital funding partnership created to fund the Games planning and delivery. Final amounts provided by Audit Scotland's (2015) post-Games report stated that:

The Scottish Government and Glasgow City Council were the main funding providers, committing up to $£ 382$ million and $£ 80$ million respectively, around 80 per cent of the total Games budget. The Organising Committee was responsible for raising the remaining 20 per cent through private income such as ticket sales, sponsorship and broadcasting rights. (p. 8)

In the context of the Games, Rogerson (2016) referred to a table from the Glasgow bid document in framing Glasgow's position within current major event legacy research. Rogerson's (2016) findings suggested Glasgow approached legacy from a much 
more structured angle than previous major events. Emphasized through the integrated approach taken by the host city, where the importance of legacy and its purpose was cohesive in all planning and delivery decisions, this structured approach was initiated from the beginning when planning for legacy was integrated into event preparation with all major partners involved in the Games delivery. Moreover, this approach represented a considered attempt to "ensure that many facets of legacies are well-planned, visible and monitored than has been used in previous mega-events” (Rogerson, 2016, p. 504). Christie and Gibb (2015) suggested that the structured approach to legacy taken by Glasgow emphasizes the need for accountability, access to resources, shared learning, and community involvement. This approach was managed through a "complex governance network" (Christie \& Gibb 2015, p. 879), which takes into consideration complex dynamics between multiple stakeholders and differing strategies, and overall represents the GLF.

This article begins by setting the context for governance in event legacy planning through the imprecise concept of legacy. The multiple understandings of what event legacies are provide a complex discussion on how the notion of event legacy, which has become a major element in bidding and delivery, is to be understood in order to successfully plan, govern, and achieve optimal event outcomes. This article focuses on Glasgow as the host city of the 2014 Commonwealth Games to investigate the way major event legacy is planned and governed from stakeholders' perspectives. By doing so, this article aims to introduce further understanding and guidance for future host cities and governing stakeholders of major events.

\section{Literature Review}

Overall, while the field of legacy research continues to witness development in many areas, there remain discrepancies in the conceptualization of legacy. Growth in areas such as community involvement (Smith, 2012), legacy governance (Christie \& Gibb, 2015), social legacy (Liu, 2014), long-term legacy planning (Rogerson, 2016), and measuring legacies (Preuss, 2007) have all established critical pathways towards understanding event legacy; however, Gratton and Preuss' (2008) definition of legacy remains a commonly utilized conceptualization of the notion.

Christie and Gibb (2015) suggested the growth of legacy planning research overlaps with current trends in urban governance regarding collaborative working. By highlighting the need to communicate effectively across multistakeholder partnerships, this emphasizes the importance for successful network management to promote further understanding of event regeneration and legacy planning amongst all stakeholders (Leopkey \& Parent, 2016). Preuss (2015) argues that governments "must start with good city planning, to fit the event into long-term city development” (p. 661). Likewise, Sadd (2010) stated that to achieve a sustainable legacy, "all the objectives of the various stakeholders need to be addressed and holistic approach taken” (p. 266). Clark and Kearns (2015) argued that clear legacy governance frameworks and structures to aid evaluation have grown in importance and complexity aligned with the expansion of legacy initiative and ambitions. Similarly, Girginov (2012) advised that strong governance systems are required to provide direction towards the collective legacy goals of delivering any social, economic, or sporting legacies for various stakeholders involved. However, the addition of newly formed governance structures can be said to add to the already complex management of Games legacy (Girginov, 2012; Stewart \& Rayner, 2016).

The post-Games legacy commitment is commonly referred to within literature in various contexts from key strategies (Davies, 2012) to sport development (Frawley \& Toohey, 2009) and discrepancies between bidding and delivery (Stewart \& Rayner, 2016); however, Solberg (2003) proposed that many organizing committees are disbanded within a short space of time after the event concludes. Therefore, it is argued that there must be a sustained commitment of resources from the host city governing bodies to realize legacy ambitions. In the context of Glasgow, Christie and Gibb (2015) argued:

As part of Glasgow City Council's (GCC) strategic remit, a dedicated 2014 legacy strategy was launched in 2009: the Glasgow Legacy Framework (Glasgow City Council, 2009), with the same Audit Scotland report setting out the requirements for clear governance structures for legacy delivery. The Glasgow Legacy Framework (GLF) 
covers a 10-year period up to 2019 and ensures that planning for a lasting legacy is fully embedded into all GCC's core strategic activity towards 2014. The GLF also committed GCC to the establishment of legacy governance structures to support the implementation of the Legacy Framework, with the rollout and implementation of the city's legacy strategy across Glasgow following thereafter. (p. 877)

The post-Games commitment to ensure the legacy plans are resourced well and continued is what Solberg (2013) suggested ultimately forms the Games' legacy reputation and successes. Here, the element of time plays a role in what legacy is defined as for a host city, and when it is said to be managed until (Stewart \& Rayner, 2016). The success of the post-Games legacy plans is said to depend on the strength of pre-Games partnerships and governance to ensure postevent considerations are fully measured and adequate resourced (Christie \& Gibb, 2015).

Research suggests when legacy plans are implemented into wider regeneration strategies, they seem to leave a more positive overall legacy (Davies, 2012; Gratton \& Preuss, 2008; Smith \& Fox, 2007). This is in contrast with what was implemented in previous host cities. For example, this was found to be the case for Sydney 2000 Olympic Games, where there were delayed regeneration plans resulting from a lack of wider legacy planning (Davies, 2012). Furthermore, Stewart and Rayner (2016) suggested integrated legacy planning allows for legacy governance and responsibilities to be decided pre-Games when working between multiple governing and planning bodies. However, Gaffney (2016) suggested integration alone without thorough forethought and community consultations does not tend to result in a positive event-led regeneration legacy, as exemplified in Brazil from the Pan American Games 2007, FIFA World Cup 2014, and Olympic and Paralympic Games 2016, where postevent usage of facilities has been questionable in necessity and appropriateness or the host community's future needs.

Currently, both the Scottish Government and Glasgow City Council's legacy frameworks monitor and evaluate Games legacy until 2019 (Glasgow City Council, 2009; Scottish Government, 2014). The frameworks recognize the importance of the Scottish economy, physical activity, international presence, and sustainability as well as accessibility and inclusivity (see Table 1). Crucially, both legacy frameworks highlight the importance of integrated planning and overall legacy governance (Smith, 2012). However, there remains a risk of difficulties in achieving legacy responsibilities due to "complicated government and political structures” (Stewart \& Rayner, 2016, p. 171), especially with regard to stakeholder management.

For this research, importance is placed on the approach taken in Glasgow by the City Council; however, this is not without regard to the governmental themes (Table 1). Although these government and council themes were initially separate and align with differing national and local government priorities, through the legacy planning and reporting process, they have become more coherent, enabling the post-Games publication of a single shared report (Scottish Government, 2015).

The GLF, established in 2009, details the legacy governance and leadership structure developed by Glasgow City Council. For the purpose of this study, the production of such a document is essential to the aim of understanding the planning and

Table 1

Legacy Frameworks (Glasgow City Council, 2009; Scottish Government, 2014)

\begin{tabular}{lc}
\hline Glasgow City Council Legacy Themes & Scottish Government Legacy Themes \\
\hline Prosperous Glasgow & Flourishing \\
Active Glasgow & Active \\
International Glasgow & Connected \\
Greener Glasgow & Sustainable \\
Accessible Glasgow & \\
Inclusive Glasgow & \\
\hline
\end{tabular}


governance of event legacies. Specifically, Christie and Gibb (2015) discussed the "major consultation exercise” undertaken by Glasgow City Council to highlight and engage with the community's aspirations and expectations. This legacy agenda presents an aligned approach to recent research carried out by Misener, Taks, Chalip, and Green (2015), who suggested, "the emphasis of legacy programs has shifted to sustainable legacies of events that emphasize broader community benefits” (p. 451). The commitment to community engagement through the legacy identification process emphasizes the importance placed on managing and governing planned legacy to enable a strong chance of creating a sustainable legacy. In addition to the frameworks developed, Glasgow launched the Glasgow Legacy Board. Detailed in the GLF, the Glasgow Legacy Board was established to lead on the development and delivery of the key legacy projects and programs, in line with the six legacy themes (Glasgow City Council, 2009); therefore, the board provided governance to the events-led economic and social initiatives integrated into the existing city regeneration strategies (Christie \& Gibb, 2015).

Also, the Games presented further innovative development by establishing an Engagement and Legacy Team embedded in their structure, an addition that is becoming increasingly common with other large sporting event structures (Misener et al., 2015), but a first for any Commonwealth Games host city (Scottish Government, 2014; Glasgow City Council, 2015). Combined with the launch of the Glasgow Legacy Board, the creation of a dedicated legacy team made Glasgow 2014 OC the first to be held accountable for the delivery of legacy outcomes (Christie \& Gibb, 2015). Although suggested by Misener et al. (2015) that the creation of Legacy Team embedded within a Games organization structure may be becoming more commonplace, the unusual nature of this is worth noting.

The Scottish Government and Glasgow City Council acknowledge that evidence on legacy from major sporting events varies in quality and thoroughness (Scottish Government, 2014; Scottish Government, 2015). However, Misener et al. (2015) described Glasgow's approach to developing legacy planning and delivery as "forthright in expressing the view that the Games provided a model for future hosts to follow with respect to legacy” (p. 457). This argument is reiterated in the Legacy 2014 (2015) post-Games report that commends Glasgow's advanced approach of officially including legacy as a factor of the OC's remit. Similarly, despite previous contested evidence heralding the challenges of securing a focused legacy (see Minnaert, 2012; Preuss, 2007; Weed, 2014), Glasgow's effort has been arguably well received within local businesses (Clyde Gateway, 2016; Legacy 2014, 2015) and research (Clark \& Kearns, 2015; Misener et al., 2015).

Although the advancement of legacy planning is apparent (Cashman \& Horne, 2013; Christie \& Gibb, 2015; Leopkey \& Parent, 2016), some authors have begun to question the number of organizations involved and their purpose. Muller (2015) stated that mega-events, such as the Olympic Games, are partly categorized accordingly to their large number of stakeholders. Difficulties in managing a group of organizations with different interests can result in implications for the host city such as lack of engagement from stakeholders (Brown, Hoye, \& Nicholson, 2012), changes in priorities (Stewart \& Rayner, 2016), and managing a diverse range of demands (Müller, 2015). Cashman and Horne (2013) analyzed this issue as "somewhat bewildering alphabet soup” (p. 57) and provided an example of organizations from the London 2012 Olympic Games (London 2012) legacy and regeneration planning. There are 10 organizations cited: these include, but are not limited to, the Olympic Delivery Authority (ODA) The Department of Culture, Media, and Sport (DCMS)/Government Olympic Executive (GOE), and Olympic Park Regeneration Steering Group (OPRSG) (see Cashman \& Horne, 2013). The wide range of stakeholders and organization involved in the legacy planning of London 2012 is a main reason Cashman and Horne (2013) questioned the ability of a successful legacy due to the varying remits and concerns. Similarly, these concerns are echoed by Davies (2012) and Stewart and Rayner (2016), who presented potential implications from the complexity of governance such as time pressure due to the lengthy and time-consuming processes involved in multistakeholder decision making, stakeholder agreement, and communication. Brown et al. (2012) suggested one response to the number of stakeholders involved in legacy governance is the emergence of overarching games 
boards to provide a structure promoting partnership and collaboration.

Within major event legacy implementation and planning, London 2012 is widely acknowledged as a turning point (Girginov, 2012; Rogerson, 2016; Weed, 2014). Likewise, Rogerson (2016) stated, "recent research, largely but not exclusively around the London 2012 experience, has cast the spotlight on the need for deeper understanding of the processes through which event legacy is articulated and planned for in advance of the event (p. 4). This more recent research can be seen to build upon Taylor and Edmondson's (2007) pre-London 2012 study concerning the emergence of legacy planning and the accompanying importance placed on legacy plans from both governing bodies and bidding teams. Similarly, as discussed by McGillivray et al. (2015), debating the most appropriate legacy approaches for before, during, and after the Games is a very current conversation. The authors stated that sporting and cultural events are a useful tool to encourage transformations and change city perceptions of host cities and countries; however, the use of events is disputed and questions are often raised about the significance of such events and who the real beneficiaries are, if not the people and places impacted by their delivery (McGillivray et al., 2015).

Rogerson (2016) suggested that although there are differences among event governing bodies and the scale of major events, "the broad approach has become increasingly similar” (p. 4). He stated parallels can be drawn at each stage of the event from pre-Games bidding, prepreparation Games delivery, and post-Games evaluation. Essentially, setting out an event legacy formula that sees cities anticipating legacies to strengthen their bid, providing legacy preparation deadlines up to the Games start date, and detailing how potential identified legacies will be measured post-Games. By highlighting this in a Commonwealth Games context, there is a suggestion towards an advancement in legacy planning within a Commonwealth Games scale to similar terms of those previously discussed in Olympic terms (Veal, Toohey, \& Frawley, 2013). Also, the range and number of stakeholders is aligned with Davies (2012), stating that to increase the likelihood of a positive legacy, multilevel stakeholder governance is required while pursuing the overall legacy ambition collectively. Christie and Gibb (2015) recognized Glasgow's involvement in the advancement of legacy planning and governance through several policies specific to legacy generation to encourage collaborative partnerships from the bidding stage. In terms of regeneration, Glasgow's approach echoes a familiar horizontal partnership relationship; however, this approach for wider Games-related legacies has, to date, been credited as exemplifying successful partnership working (Audit Scotland, 2012; Commonwealth Games Federation, 2012). A characteristic of its distinctiveness has been the bringing together of a range of complex partnerships into one governance structure. This also speaks to the extent to which new partnership structures have been successful or limited by the Glasgow context, historical and other place-specific factors, and is arguably important to understanding the constraints facing partnerships more generally (Christie \& Gibb, 2015). Despite the potential contextual specifics that cannot be replicated in any host city, this article draws from literature adding to the critical commentary on governance within event legacy exemplifying that understanding the importance of efficient collaboration pre- and post-Games can not only achieve a successful approach to legacy, but also foster partnerships that can be utilized post-Games within the host city.

Furthermore, Rogerson's (2016) research presents "three key elements of an innovative approach to legacy creation” (p. 12) from Glasgow’s method of legacy planning. Outlined by the author, a key element to Glasgow's approach was that the responsibility for managing the build was placed upon Glasgow City Council. This allowed for a long-term, holistic view of legacy planning to be designed for the city and enabled a level of local ownership over spending. More commonly among major events, the legacy leadership role is combined within the organizing committee's remit or contracted to a specific development organization. Leopkey and Parent (2012) highlighted the outsourcing of legacy planning as an issue for post-Games legacy planning because organizing committees are a temporary structure quickly disbanded postGames, and legacies require a much longer time to evaluate. Therefore, unlike the approach taken by organizing committees in London 2012 or the 2010 
Delhi Commonwealth Games (Girginov, 2012), Glasgow's method demonstrates original thinking to aid future legacy evaluation and design.

\section{Methods}

This research examines the Games as a current example providing successful insights into legacy governance. Qualitative methodological approaches inform the case study. This research emphasizes the diverse range of stakeholders within a Commonwealth Games host city linked to the potential to create legacies. To achieve this, 14 in-depth interviews were conducted ranging from $45 \mathrm{~min}$ to 80 min in length with key Games-related organizations from December 2014 to June 2016, usually conducted at the interviewee's workplace. It was pertinent to this research to gain access to a broad range of stakeholders to analyze varying perspectives. Creswell, Hanson, Clark Plano, and Morales (2007) stated key informant interviewees are "gatekeepers," often deemed well informed and are able to provide opportunities leading to new information. For this research, the interviews provided an opportunity to put legacy in a local context and explore key insights into Glasgow's legacy imperative. This type of interview draws vital information from a variety of people who have relevant expertise and experience of their respective situations; therefore, the intention behind this method was to gain key stakeholder insights into legacy planning and implications for Glasgow as a host city.
Therefore, to gain in-depth data for the proposed study, the interview participants $(n=14)$ were from programs or organizations associated with legacy programs and planning, and community engagement. These include organizations such as the OC, Glasgow City Council, Clyde Gateway Regeneration Agency, Glasgow Centre for Population Health, Sports Scotland, Volunteer Scotland, Community Learning Campus, Council Legacy Hub Coordinator, and Glasgow Life (see Table 2). As this article is part of a larger body of work, the findings reflect the participant voices that are most relevant and helpful for focusing on governance.

Each interviewee was engaged throughout the conversation, providing key insights based on their expertise into their role and experience of Glasgow's approach to hosting the Commonwealth Games. Guided by Saunders, Lewis, and Thornhill's (2007) research phases of thematic analysis, the author then categorized the data into the themes through making notes and highlighting appropriate sections. The interview questions asked were based on the importance of legacy planning (the planning process pre-, during, and post-Games), partnerships involved (working partnerships, engagement with other stakeholders including the local community, and community groups), and Glasgow as a host city (regarding perspectives on both Glasgow City Council and Glasgow 2014 OC). Throughout this process, the emerging relationships between the data were recognized and used to develop overall conclusion relating to the theme and research

Table 2

Interviewee by Job Role and Representative Organization

\begin{tabular}{ll}
\hline Interviewee by Participant Number & \multicolumn{1}{c}{ Organization Category } \\
\hline Interview participant 1 (IP1) & Local authority \\
Interview participant 2 (IP2) & Voluntary sector organization \\
Interview participant 3 (IP3) & Games Organizing Committee \\
Interview participant 4 (IP4) & Local author partnership organization \\
Interview participant 5 (IP5) & Community organization \\
Interview participant 6 (IP6) & Community organization \\
Interview participant 7 (IP7) & Sport governing body \\
Interview participant 8 (IP8) & Social research organization \\
Interview participant 9 (IP9) & Community association \\
Interview participant 10 (IP10) & Volunteer program Glasgow 2014 \\
Interview participant 11 (IP11) & Local authority Legacy Hub \\
Interview participant 12 (IP12) & Voluntary organization leader Glasgow 2014/volunteer \\
Interview participant 13 (IP13) & Public sector organization \\
Interview participant 14 (IP14) & Public sector organization \\
\hline
\end{tabular}


objectives. Thematic analysis is known to be used in situations where there is a lack of previous research in the subject area and therefore code categories are derived straight from the text data itself. For this research, the notes and transcripts were word processed and the data analysis software NVivo 10 was used. The software enabled greater development and connection while making the whole analysis process faster and more efficient (Bryman, 2012). The themes emerging from the data collected identified three key areas: conceptualizing and understanding what legacy means, planning legacy, and the implications for stakeholders of legacy planning. Overall, the interviews provided an opportunity to situate legacy in the local context of Glasgow.

\section{Analysis and Results}

\section{(Mis)Understanding Legacy}

There is enormous variation of so-called legacies within the literature from sports events. However, although often used, the concept of legacy is rarely defined within academic and nonacademic literature (Chappelet, 2014; Gratton \& Preuss, 2008). The beginning of this analysis provides an examination of how legacy is understood by the stakeholders interviewed before closer examination into the impact this has on understanding legacy planning and governance.

With regard to the Games, Glasgow City Council (2009) and the Scottish Government produced a Legacy Framework 5 years pre-Games defining legacy as:

Legacy is the set of benefits left behind well after a major event, like Glasgow 2014, has ended. Lasting benefiting will be both tangible (e.g., job opportunities; business opportunities; new infrastructure investment), and less tangible (e.g., enhanced image; civic pride; improved health; improved community engagement). (p. 6)

The framework expands upon legacy to incorporate the potential for social and economic change through inspiring and motivating individual, communities, and stakeholders to be involved in Games-related opportunities (Glasgow City Council,
2009). The pre-Games discussion surrounding the concept of legacy suggests movement towards defining legacy within industry documents; however, there remains a slight ambiguity due to Glasgow City Council and the Scottish Government both producing differing, although similar, legacy themes. Dickson, Benson, and Blackman (2011) suggested that the lack of any initial, satisfactory definition has led to the increase in legacy themes or categories. The documentation concerning the Games seems to present this dilemma; therefore, rather than produce a legacy definition, Glasgow City Council and the Scottish Government produce Games-specific ambitions and themes. These conclusions are aligned with Leopkey and Parent's (2012) examination of the increasing use of themes within hosting documents from the Olympic Games. The authors suggest themes are becoming progressively interconnected and overlapping to achieve an overall legacy goal; similar deductions are evident from the suite of official Glasgow 2014 documents due to the themes being used to describe an overall legacy vision for Glasgow and Scotland.

The majority of interviewees mentioned some confusion around defining or quantifying legacy. For example, an interviewee from a Games OC member commented when discussing what can be attributed to legacy: “There's that knock on legacy, again how to quantify it, that's the problem with legacy it's difficult to quantify" (IP3).

Similarly, an interviewee from a voluntary sector employee suggested that to conceptualize legacy, the Games in question need to undertake clear assessments and have Games-related targets: "Where maybe it's a little greyer is that I don't think there has been a realistic assessment of what actually can a Games bring about, and what can you actually nail to the Games” (IP2).

Here, the data collected agree with Cashman and Horne's (2013) issues surrounding legacy governance and "the problem of legacy assessment" (p. 50). The authors suggested that although legacy governance has progressed, current issues facing successful legacy planning include monitoring, policing, and research legacy management (Leopkey \& Parent, 2012). Cashman and Horne (2013) also presented the issue of the lengthy descriptions 
and variety of legacies. An interviewee describes the difficulties surround the diffuse nature of legacy:

I think the term legacy causes some confusing and the branding of legacy, I think it helps to describe it as something already exists and show how it works already . . . explaining this is what happens and it's called legacy what you are actually doing. . . . From my experience as soon as you mention the word legacy they think it's something new. (IP11)

This demonstrates a pathway taken within a community setting to avoid confusion through legacy terminology; moreover, it also provides insight into a real-life example of explaining what legacy is in the context of the Games.

Findings from this study suggest that, despite developing legacy themes from a core vision, stakeholders still struggle to understand the concept of legacy, especially at a local community level. Confusion appears evident from the outset in terms of defining what legacy will mean for local people, with data suggesting that interviewees did have a grasp of the notion of a successful legacy, but were not entirely sure of how that related to their lives nor the details of how that would change things for them. For example, they saw improvements being made to their local area, but did not readily link those positive changes with Commonwealth Games legacy. Specifically, this suggests the concept of legacy is not yet easily accessible to those who are arguably a target audience- - the host community.

\section{Legacy Planning}

Examined in the literature review, planning for legacy is an emerging area of event legacy research (Christie \& Gibb, 2015). As a means to evaluate event-led regeneration legacy governance, Christie and Gibb (2015) provided six crucial elements for securing effective partnerships: "the pooling of resources and shared agendas, leadership, community engagement, mutual learning, accountability and trust” (p. 883). The authors summarized their findings by presenting Glasgow as example of successful event-legacy planning and governance to educate future host cities. This section critically analyzes the data collected for this study as evidence to further inform legacy planning governance and delivery. For example, an interview with a voluntary sector employee stated:

I think from the outset, I'd like to commend the Scottish Government for having the foresight to have Shona Robinson as a dedicated minister for the Commonwealth Games and she saw that through and gave personality and political weight behind how important these games were. So that personal spearheading of things and her influence over sportScotland and young engagement, she really gave meaning to legacy in a way that London never came close to actually. So, we've had this twin track thing about delivering the games but also genuinely delivering a legacy as well. (IP2)

Here, the interviewee credits the innovative approach to legacy planning of appointing a Commonwealth Games and Sport Minister, thus emphasizing what the Commonwealth Games Federation now acknowledge as the Glasgow approach (see Rogerson, 2016). The notion of legacy accountability was present in the data, notably from an interview with Glasgow Centre for Population Health regarding their thoughts on regeneration legacy:

I think it's been exceptional, really, really good and part of that is from having champions which were really bolshie and pushy and keep getting in people face and asking what have you done about this so there is some sort of accountability for different partners and they may not like it that much but it gets it done. (IP8)

This interviewee presents the need for major event hosts to have a visible point of contact for legacy decisions, both for the communities affected and for the purpose of ensuring each stakeholder takes responsibility for their part in Games delivery. Additionally, the data in this study reinforce the importance in community-centered legacy planning. Interviewees from each organization contacted spoke of the importance placed in community development and support pre-, during, and postGames. The data from this study further emphasize that this was a crucial decision for the majority of interviewees in advancing the field of major event legacy planning and delivery. 
From the data collected, the majority consensus was in support of the approach Glasgow had taken to ensuring pre-, during, and post-Games evaluation and measurement. An employee from a voluntary sector organization commended the governmental leadership’s planning for legacy outcomes:

Another strength I would say is the interest from the Government and ensuring there was a proper measuring framework for what legacy would be. That has been really excellent, there was very thorough work done on what evidence of legacy had there been in other places and that fitted into the programme for Government around welfare and healthier, smarter, so it was good alignment with that and there's been a lot of notable successes that have already happened, e.g. the sporting legacy hubs in Scotland and also Clyde Gateway and investment there. (IP2)

Here, the data in this study support Preuss' (2007) recommendation that cities deciding to bid must complete thorough research in advance in order to identify gaps and inform strategic plans. Following from the example set by London 2012 as a preeminent instance of legacy planning, Glasgow and the Commonwealth Games extended the development of legacy planning to now include post-Games elements in the bid stage. Despite London 2012 facing criticism that a number of the promised legacy elements were compromised due to funding decisions, the element of legacy evaluation at the bid stage was said to help win the bid for the city (Scottish Government, 2014). Similarly, the data in this study suggest the lessons to be learned from the inclusion of legacy at the bid stage are crucial to the development of this field of research. This supports Leopkey and Parent's (2012) statement, “The change from thinking about legacy post-Games and post-bids to planning for it pre-Games is one of the most significant evolutional adaptations in the governance of legacy within the modern Olympic Games” (p. 938).

\section{Discussion}

This article provides an insight into the development of legacy planning for major events and the emergence of a partnership legacy from stakeholder perspectives. Focusing on understanding legacy, planning for legacy, and legacy implications, the three key themes emerging from thematic data analysis were: 1) the issues presented in understanding the concept of legacy across all stakeholders; 2) the importance and development of legacy planning and governance for the Games; and 3) the impacts Glasgow's approach to legacy has had on stakeholders. A key conclusion from this is the notion of a partnership legacy can be seen to have grown from innovative legacy governance structures put in place by Glasgow in the early stages of legacy planning. When considering lessons learned for Glasgow from an interviewee from the local authority, there is an emphasis on the potential impact for the city from stronger working relationships and partnerships:

For me, having a better understanding of partnership working. So, legacy for me is I now know how we can do things better by having a multiagency approach than just organisations coming together as and when necessary. That's for me a real lesson learned. (IP1)

Here, the real future implications for Glasgow's event-hosting approach is aligned with the growing body of research highlighting the importance of strong collaborations and networks (Christie \& Gibb, 2015; Skinner, Zakus, \& Cowell, 2008; Smith, 2009; Swart, Bob, Knott, \& Salie, 2011). The multiagency approach mentioned in the above quotation mirrors the research by Bornstein (2010), which suggested the practicality of such an approach to manage complex projects. Although research suggests a mixed history in realizing promised benefits despite building networks between stakeholders (Sadd, 2009; Davidson \& McNeill, 2012), the data here agree with Christie and Gibb's (2015) conclusion that Glasgow has produced a successful example of partnership development and sustainability, therefore informing broader working relationships city wide. It is suggested that the building and maintaining of such partnerships from a major event has the potential to initiate an additional type of social partnership legacy between communities, organizations, and individuals.

The challenges facing forward-thinking host cities, event professionals, and governments when considering legacy planning and implementation are unsurprising considering the mixed legacy conceptualizations and typologies (Leopkey \& Parent, 2012). Cashman and Horne (2013) provided a 
much-needed review of "legacy-management processes that have emerged in the last decade” (p. 50). Preuss (2015) stated that changes associated with legacies are apparent from the time of an event being awarded; therefore, it is imperative legacy is planned. The data collected in this study across all 14 interviews was in agreement for efficient and flexible legacy planning. Cashman and Horne (2013) suggested that the methods of planning and managing legacy remain in the developmental stage with gaps and weaknesses apparent such as ensuring planning is a central component, securing a long-term focus and relevant evaluation, and managing stakeholder outcomes and resource challenges. Arguably, this is due to the recent emergence of this research field and differences in priorities from organizing bodies (Stewart \& Rayner, 2016). Data from this study suggest this is an area Glasgow approached from the bid stage by setting out clear legacy evaluation timelines and methods.

Misener, Darcy, Legg, and Gilbert (2013) defined legacy planning as "developing enduring, long-term positive benefits usually on a regional or national scale because the funder is typically a government agency” (p. 239). Rogerson (2016) advocated the importance of a strategic management approach to legacy planning; however, he cautioned that "even careful planning may not be sufficient and one of the key lessons emerging from the London experience has been the limited action towards legacy in the years leading up to the event” (p. 4). Thus, this provides further recognition of the importance of legacy governance and management preevent to realize and sustain ambitious legacy outcomes; hence, supporting the findings in this research claiming Glasgow recognized the need to consider legacy responsibility and governance into the pre-Games structures.

Although one example of major event legacy planning and governance cannot be taken in isolation, previous research and the findings of this study suggest innovative developments within legacy generation and major event management such as embedding a Legacy team within the organizing committee of a Commonwealth Games and employing a Minister for Legacy and Sport. Furthermore, data collected from a local authority interviewee suggest that the scale of these Games for Glasgow allowed partnerships to be created city wide. By establishing a robust, working relationships across organizations, communities, and individuals, a real and powerful sense of ownership is achievable, as witnessed within Glasgow's approach to legacy planning. Although legacy research highlights the potential for unplanned legacies, in the case of Glasgow, the findings in this research highlight the potential within host cities to create a partnership legacy that is wide reaching through new and established network development. Consistent with Leopkey and Parent (2016) and Christie and Gibb (2015), this research proposes Glasgow has the potential to create a partnership legacy grown from innovative legacy governance, collaborative working, and network creation. The element of building such stakeholder relationships can be considered as a legacy in itself for the future of the host city.

\section{Conclusions}

When considering the planning element of legacy, this research confirms the need for strong legacy planning to realize overall legacy aims. Furthermore, this research proposed Glasgow has the potential to create a partnership legacy grown from innovative legacy governance, collaborative working, and network creation. Aligned with the key themes emerging from the data collected, conclusions can be drawn regarding the importance of establishing clear legacy plans pre-Games. Furthermore, the significance of Games-time stakeholder partnerships must be acknowledged as a possible legacy for the host city. It also is suggested from this research that sufficient time and integration strategies are vital to build an informed legacy agenda to ensure all stakeholder responsibility and governance is well communicated. Importantly, this article frames the legacy discussion in the understanding of legacy planning and governance, which highlights the need for impact recognition pre-Games to create longevity towards legacy achievement.

A further conclusion drawn from this research emphasizes the importance of the notion of a created partnership legacy from hosting a major event. Notably, advances in major event planning are evident in a number of areas including venue access, integrated legacy team, bidding awareness, community engagement, and partnership creation from 
Glasgow's approach. Further research is needed to examine the links between increased social capital and games partnership legacy; however, findings from this study present encouraging results as to the impacts of creating trusted, strong relationships within a city. Lastly, to further legacy understanding and analysis, it is recommended further research focus on the evolution of event legacy from different major event perspectives, such as other sporting events (e.g., FIFA World Cup, Rugby World Cup) in order to identify current games governance structures and the implication said structure have on legacy planning, implementation, and evaluation.

\section{References}

Audit Scotland. (2012). Commonwealth Games 2014. Edinburgh, Scotland: Audit Scotland.

Audit Scotland. (2015). Commonwealth Games 2014: Third report. Edinburgh, Scotland: Audit Scotland.

Bornstein, L. (2010). Mega-projects, city-building and community benefits. City, Culture and Society, 1(4), 199-206.

Brown, K. M., Hoye, R., \& Nicholson, M. (2012). Selfesteem, self-efficacy, and social connectedness as mediators of the relationship between volunteering and well-being. Journal of Social Service Research, 38(4), 468-483.

Bryman, A. (2012). Social research methods. Oxford, UK: University Press.

Cashman, R., \& Horne, J. (2013). Managing legacy. In S. Frawley \& D. Adair (Eds.), Managing the Olympics (pp. 50-65). London, UK: Springer.

Chappelet, J. (2014). Managing the size of the Olympic Games. Sport in Society, 17(5), 581-592.

Christie, L., \& Gibb, K. (2015). A collaborative approach to event-led regeneration: The governance of legacy from the 2014 Commonwealth Games. Local Economy, 30(8), 871-887.

Clark, J., \& Kearns, A. (2015). Pathways to a physical activity legacy: Assessing the regeneration potential of multi-sport events using a prospective approach. Local Economy, 30(8), 888-909.

Clyde Gateway. (2016, December 20). Building the Legacy. Retrieved from http://www.clydegateway.com/CG\%20 ANNUAL_REPORT_15-16_WEB.pdf

Coaffee, J. (2013). Policy transfer, regeneration legacy and the summer Olympic Games: Lessons for London 2012 and beyond. International Journal of Sport Policy and Politics, 5(2), 295-311.

Commonwealth Games Federation. (2012). Glasgow 2014 legacy framework. Glasgow, Scotland: Commonwealth Games Federation \& Glasgow City Council.

Creswell, J. W., Hanson, W. E., Clark Plano, V. L., \& Morales, A. (2007). Qualitative research designs:
Selection and implementation. The Counseling Psychologist, 35(2), 236-264.

Davidson, M., \& McNeill, D. (2012). The redevelopment of Olympic sites: Examining the legacy of Sydney Olympic park. Urban Studies, 49(8), 1625-1641.

Davies, L. E. (2012). Beyond the games: Regeneration legacies and London 2012. Leisure Studies, 31(3), 309-337.

Dickson, T. J., Benson, A. M., \& Blackman, D. A. (2011). Developing a framework for evaluating Olympic and Paralympic legacies. Journal of Sport \& Tourism, 16(4), 285-302.

Frawley, S., \& Toohey, K. (2009). The importance of prior knowledge: The Australian Olympic committee and the Sydney 2000 Olympic Games. Sport in Society, 12(7), 947-966.

Gaffney, C. (2016). An anatomy of resistance: The popular committees of the FIFA world cup in Brazil. In J. Dart \& S. Wagg (Eds.), Sport, protest and globalisation (pp. 335-363). London, UK: Springer.

Girginov, V. (2012). Governance of the London 2012 Olympic Games legacy. International Review for the Sociology of Sport, 47(5), 543-558.

Glasgow City Council. (2009). Glasgow 2014 legacy framework. Glasgow, Scotland: Glasgow City Council.

Glasgow City Council. (2015). Glasgow 2014 legacy framework: A Games legacy for Glasgow. Glasgow, Scotland: Glasgow City Council.

Gratton, C., \& Preuss, H. (2008). Maximizing Olympic impacts by building up legacies. The International Journal of the History of Sport, 25(14), 1922-1938.

Jones, R., \& Yates, G. (2015). Pre-Games expectations and past volunteering experiences of Glasgow 2014 Clydesider applicants. Glasgow, Scotland: Glasgow Centre of Population Health.

Legacy 2014. (2015). An evaluation of the Commonwealth Games 2014 legacy for Scotland. Glasgow, Scotland: Legacy Partnership.

Lenskyj, H. (2002). The best Olympics ever? Social impacts of Sydney 2000. Albany, NY: SUNY Press.

Leopkey, B., \& Parent, M. M. (2012). Olympic Games legacy: From general benefits to sustainable long-term legacy. The International Journal of the History of Sport, 29(6), 924-943.

Leopkey, B., \& Parent, M. M. (2016). The governance of Olympic legacy: Process, actors and mechanisms. Leisure Studies, 36(3), 1-14.

Liu, Y.-D. (2014). Cultural events and cultural tourism development: Lessons from the European capitals of culture. European Planning Studies, 22(3), 498-514.

McCartney, G., Hanlon, P., \& Bond, L. (2013). How will the 2014 Commonwealth Games impact on Glasgow's health, and how will we know? Evaluation, 19(1), 24-39.

McGillivray, D., McPherson, G., \& Carnicelli, S. (2015). Sporting and cultural events: Contested legacies. Annals of Leisure Research, 18(4), 441-444.

Minnaert, L. (2012). An Olympic legacy for all? The non-infrastructural outcomes of the Olympic Games for 
socially excluded groups (Atlanta 1996-Beijing 2008). Tourism Management, 33(2), 361-370.

Misener, L., Darcy, S., Legg, D., \& Gilbert, K. (2013). Beyond Olympic legacy: Understanding Paralympic legacy through a thematic analysis. Journal of Sport Management, 27(4), 329-341.

Misener, L., Taks, M., Chalip, L., \& Green, B. C. (2015). The elusive "trickle-down effect” of sport events: Assumptions and missed opportunities. Managing Sport and Leisure, 20(2), 135-156.

Müller, M. (2015). What makes an event a mega-event? Definitions and sizes. Leisure Studies, 34(6), 627-642.

Preuss, H. (2007). The conceptualisation and measurement of mega sport event legacies. Journal of Sport \& Tourism, 12(3-4), 207-228.

Preuss, H. (2015). A framework for identifying the legacies of a mega sport event. Leisure Studies, 34(6), 643-664.

Rogerson, R. (2016). Re-defining temporal notions of event legacy: Lessons from Glasgow's Commonwealth Games. Annals of Leisure Research, 19(4), 1-22.

Sadd, D. D. (2010). What is event-led regeneration? are we confusing terminology or will London 2012 be the first games to truly benefit the local existing population? Event Management, 13(4), 265-275.

Saunders, M., Lewis, P., \& Thornhill, A. (2007). Research methods for business students. Harlow, UK: Pearson Education.

Scottish Government. (2014). An evaluation of legacy from the Glasgow 2014 Commonwealth Games. Edinburgh, Scotland: Author.

Scottish Government. (2015). an evaluation of legacy from the Glasgow 2014 Commonwealth Games: Post Games Report. Edinburgh, Scotland: Author.

Scottish Government, Games Legacy Team. (2009). On your marks ... A games legacy for Scotland. Edinburgh, Scotland: The Scottish Government.

Skinner, J., Zakus, D. H., \& Cowell, J. (2008). Development through sport: Building social capital in disadvantaged communities. Sport Management Reviews, 11(3), 253-275.

Smith, A. (2009). Theorising the relationship between major sport events and social sustainability. Journal of Sport and Tourism, 14(2-3), 109-120.

Smith, A. (2012). Events and urban regeneration: The strategic use of events to revitalise cities. Oxford, UK: Routledge.

Smith, A., \& Fox, T. (2007). From “event-led" to “eventthemed” regeneration: The 2002 Commonwealth Games legacy programme. Urban Studies, 44(5-6), 1125-1143.

Solberg, H. A. (2003). Major sporting events: Assessing the value of volunteers' work. Managing Leisure, 8(1), 17-27.

Stewart, A., \& Rayner, S. (2016). Planning mega-event legacies: Uncomfortable knowledge for host cities. Planning Perspectives, 31(2), 157-179.

Swart, K., Bob, U., Knott, B., \& Salie, M. (2011). A sport and sociocultural legacy beyond 2010: A case study of the Football Foundation of South Africa. Development Southern Africa, 28(3), 415-428.

Taylor, M., \& Edmondson, I. (2007). Major sporting events-Planning for legacy. Proceedings of the Institution of Civil Engineers-Municipal Engineers, 160(4), 171-176.

Thomson, A., Schlenker, K., \& Schulenkorf, N. (2013). Conceptualizing sport event legacy. Event Management, 17(2), 111-122.

Veal, A., Toohey, K., \& Frawley, S. (2013). The sport participation legacy of the Sydney 2000 Olympic Games and other international sporting events hosted in Australia. Journal of Policy Research in Tourism, Leisure and Events, 4(2), 155-184.

Weed, M. (2014). Sports mega-events and mass participation in sport. In J. Grix (Ed.), Leveraging legacies from sports mega-events: Concepts and cases (pp. 39-49). London, UK: Springer. 